Bentham OPen
CrossMark
Content list available at: www.benthamopen.com/TOCIEJ/
DOI: $10.2174 / 1874149501812010108$

RESEARCH ARTICLE

\title{
Effect of Steel Fiber Ratios on Behavior of High Strength Hybrid Reinforced Concrete Deep Beams under Repeated Loading
}

\author{
Sawsan Akram Hassan and Ansam Hassan Mhebs ${ }^{*}$ \\ Civil Engineering Department, Al-Mustansiriayah University, Baghdad, Iraq
}

Received: January 16, 2018

Revised: April 3, 2018

Accepted: April 14, 2018

\begin{abstract}
:
Introduction:

The present work presents experimental and analytical investigation of the effect of steel fiber ratio of behavior of high strength hybrid reinforced concrete deep beams under monotonic and repeated two point load.

\section{Methods:}

The experimental work included casting and testing of six deep beams, three of which were tested under monotonic loading (control beams) and other beams were tested under repeated loading at level of $75 \%$ of ultimate load of control beams. The effect of different SF ratios $(0 \%, 1 \%$ and $2 \%)$ with constant amount of web reinforcement $\left(p_{w}\right)$ were studied in terms of crack patterns, ultimate load and load versus mid span deflection.
\end{abstract}

\section{Results and Conclusion:}

From the experimental test results, it was observed the percentage increase ultimate load for hybrid beam cast with SF ratio $1 \%$ is $9.62 \%$ as compared with hybrid beam with SF ratio $0 \%$. Also, the ultimate load for hybrid beam cast with SF ratio $2 \%$ is $28.85 \%$ as compared with hybrid beam with SF ratio $0 \%$ and $17.54 \%$ as compared with hybrid beam with SF ratio $1 \%$ under monotonic loading. Strut and Tie Model (STM) procedures were used to analyze the experimentally tested hybrid deep beams under monotonic loading of the present investigation.

Keywords: Deep beam, Hybrid, Fibrous high strength concrete, Conventional concrete, Strut and tie model, Repeated, Monotonic.

\section{INTRODUCTION}

The deep beam could be defined as associate load on the face and the inversion face. The compression elements can expand among the support and loads under ACI-Code 318R-14. The clear span and total depth ratio less than four and the shear span to depth ratio less than two [1]. There are many applications for reinforced concrete deep beams such as buildings, bridges, offshore structures and foundations. There are many structural elements which behave as a deep beam such as transfer beams, load bearing walls and coupling beams in buildings, pile caps in foundations, plate elements in the folded plates and bunker walls [2]. Beams in general are classified as shallow beams, moderate deep beams, and deep beams according to their span to depth ratios. Beams whose depths are comparable to their spans may be described as deep beams. There is a distinct change in behavior of deep beams and moderate deep beams because of the presence of local lateral normal forces in addition to usual bending moments and shear forces. This is not true for shallow beams. There is gradual transition from shallow beam behavior to deep beam behavior. In construction, deep beams are widely used in water tanks, underground bunkers, silos, nuclear reactors, where walls act as vertical beams spanning between column supports. Sometimes pile caps are also designed as deep beams. Deep beams and moderate

\footnotetext{
* Address correspondence to this author at the Civil Engineering Department, Al-Mustansiriayah University, Baghdad, Iraq, Tel: +6947712921362; E-mails: ans90ans@gmail.com; drc_sawsanakram@uomustansiriyah.edu.iq
} 
deep beams occur frequently in modern buildings such as departmental stores, hotels and theatres where it is desired to have the lower floor completely free of columns. In reinforced concrete hipped plate construction, the supporting diaphragms often behave as deep beams.

\section{EXPERIMENTAL WORK}

A total of six simply supported deep beams have been tested under two point loads to investigate the effect of steel fiber ratios of high strength hybrid reinforced concrete deep beams under monotonic and repeated loading. The tested beams must been destined to guarantee shear failure under monotonic loading according to ACI 318 R-14Code (STM). Totally beams had the similar dimensions and flexural reinforcement. They had generally span of $1500 \mathrm{~mm}$, a width of $150 \mathrm{~mm}$ and a height of $350 \mathrm{~mm}$. The quantity of flexural reinforcement for totally the tested beams was (where is the flexural reinforcement ratio). The clear span between supports was $1230 \mathrm{~mm}$ which results in a ratio of clear span to generally depth of 3.5 which is minus than 4.0 as commended by the conditions of the ACI $318 \mathrm{M}-14$ Code for deep beam requirements. As well, bearing plates under all load and over each support were designed to avoid any local crushing in concrete. Table 1 shows details of the six tested reinforced concrete deep beams in Fig. (1).

Table 1. Hybrid Deep Beam Specimens Details.

\begin{tabular}{|c|c|c|c|}
\hline Beam Designation & Type of Beams & $\begin{array}{c}\text { Type of Load } \\
\mathbf{( \% )}\end{array}$ & Monotonic \\
\hline B-HS-M-HSC $0-\rho_{w} 0$ & $\begin{array}{c}\text { Non-Hybrid } \\
\text { (HSC) }\end{array}$ & 0.0 \\
\hline B-HS-R-HSC $0-\rho_{w} 0$ & $\begin{array}{c}\text { Non-Hybrid } \\
\text { (HSC) }\end{array}$ & Repeated(75\% of Ultimate Load for Last Beam) & Monotonic \\
\hline B-HS-M-Hy1- $\rho_{w} 0$ & Hybrid & Repeated(75\% of Ultimate Load for Last Beam) \\
\hline B-HS-R-Hy1- $\rho_{w} 0$ & Hybrid & Monotonic & 0.0 \\
\hline B-HS-M-Hy2- $\rho_{w} 0$ & Hybrid & Repeated(75\% of Ultimate Load for Last Beam) & 0.0 \\
\hline B-HS-R-Hy2- $\rho_{w} 0$ & Hybrid & 2 & 0.0 \\
\hline
\end{tabular}

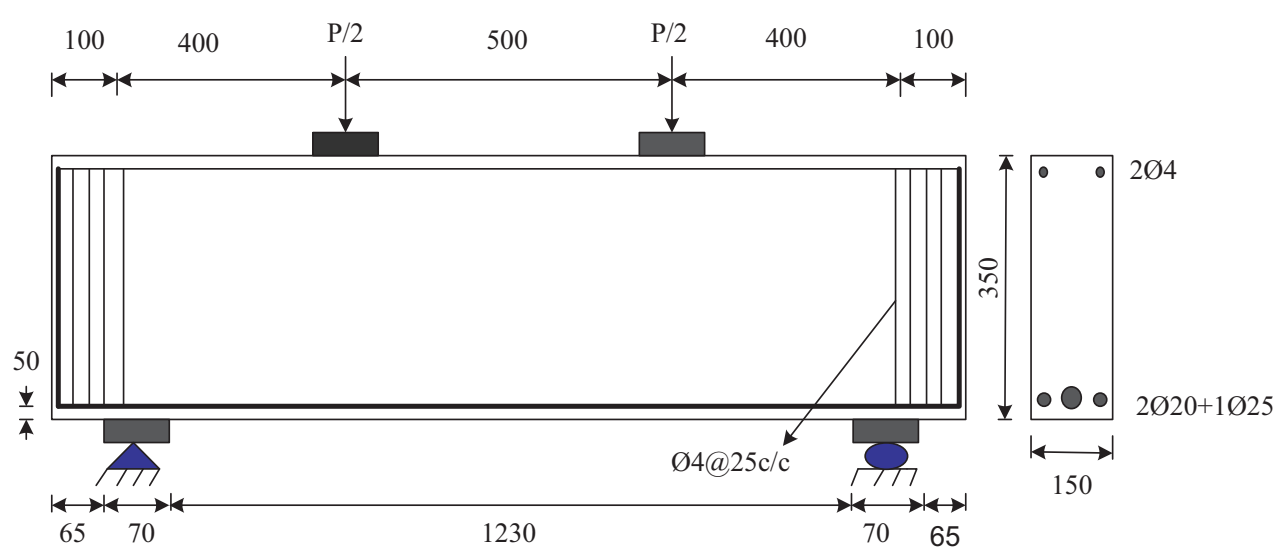

Fig. (1). Details of Beams with $\rho_{\mathrm{w}}$ 0. (All Dimensions are in $\mathrm{mm}$ ).

\section{MATERIALS AND METHODS}

\subsection{Materials}

Properties and description of used materials are reported and presented in Table $\mathbf{2}$ and the concrete proportions are reported and presented in Table 3 .

Table 2. Properties of Construction Materials.

\begin{tabular}{|c|c|}
\hline Materials & Descriptions \\
\hline Cement & Ordinary Portland Cement (Type I) \\
\hline Sand & Natural Sand from Al- Ukhaider region with Maximum size of (4.75) \\
\hline
\end{tabular}


(Table 2) contd.....

\begin{tabular}{|} 
(Table 2) contd..... \\
\begin{tabular}{|c|c|}
\hline Materials & Descriptions \\
\hline Gravel & Crushed gravel with maximum size $(12 \mathrm{~mm})$ \\
\hline Steel Fiber & $\begin{array}{c}\text { Hooked ends steel fibers are used in construction of } \\
\text { fibrous concrete with volumetric ratio } 0 \%, 1 \% \text { and } 2 \%\end{array}$ \\
\hline Steel Reinforcement & $\phi 4$ plain steel bar with yield strength $(680 \mathrm{MPa})$ \\
& $\phi 20$ deformed steel bar with yield strength $(491 \mathrm{MPa})$ \\
& $\phi 25$ deformed steel bar with yield strength $(520 \mathrm{MPa})$ \\
\hline Superplasticizer & Glenium 54 \\
\hline Water & Clean tap water \\
\hline
\end{tabular}
\end{tabular}

Table 3. Proportions of Concrete Mixes per Cubic Meter.

\begin{tabular}{|c|c|c|c|c|c|c|}
\hline $\begin{array}{l}\text { Compressive } \\
\text { Strength } \\
\text { (MPa) }\end{array}$ & $\begin{array}{l}\text { Cement } \\
\left(\mathrm{kg} / \mathrm{m}^{3}\right)\end{array}$ & $\begin{array}{c}\text { Sand } \\
\left(\mathrm{kg} / \mathrm{m}^{3}\right)\end{array}$ & $\begin{array}{c}\text { Gravel } \\
\left(\mathrm{kg} / \mathrm{m}^{3}\right)\end{array}$ & Water to Cement Ratio (w/c) & $\begin{array}{l}\text { SF } \\
(\%)\end{array}$ & $\begin{array}{c}\text { Steel Fiber } \\
\left(\mathrm{kg} / \mathrm{m}^{3}\right)\end{array}$ \\
\hline \multirow{3}{*}{60} & \multirow{3}{*}{560} & \multirow{3}{*}{635} & \multirow{3}{*}{1085} & \multirow{3}{*}{0.26} & 0 & - \\
\hline & & & & & 1 & 78 \\
\hline & & & & & 2 & 156 \\
\hline
\end{tabular}

\subsection{Molds}

Four steel molds were designed for casting four hybrid deep beams for each batch as shown in Fig. (2). The inside dimensions for each mold were $1500 \mathrm{~mm}$ length, $350 \mathrm{~mm}$ height and $150 \mathrm{~mm}$ width. The molds were designed to cast the beams vertically due to the difficulty of casting layers in horizontal state. The lower plate was fixed to cast the first layer while the two other plates above were movable (doors) to cast the two other layers. Each door was closed before casting the layer of beam in reverse it.

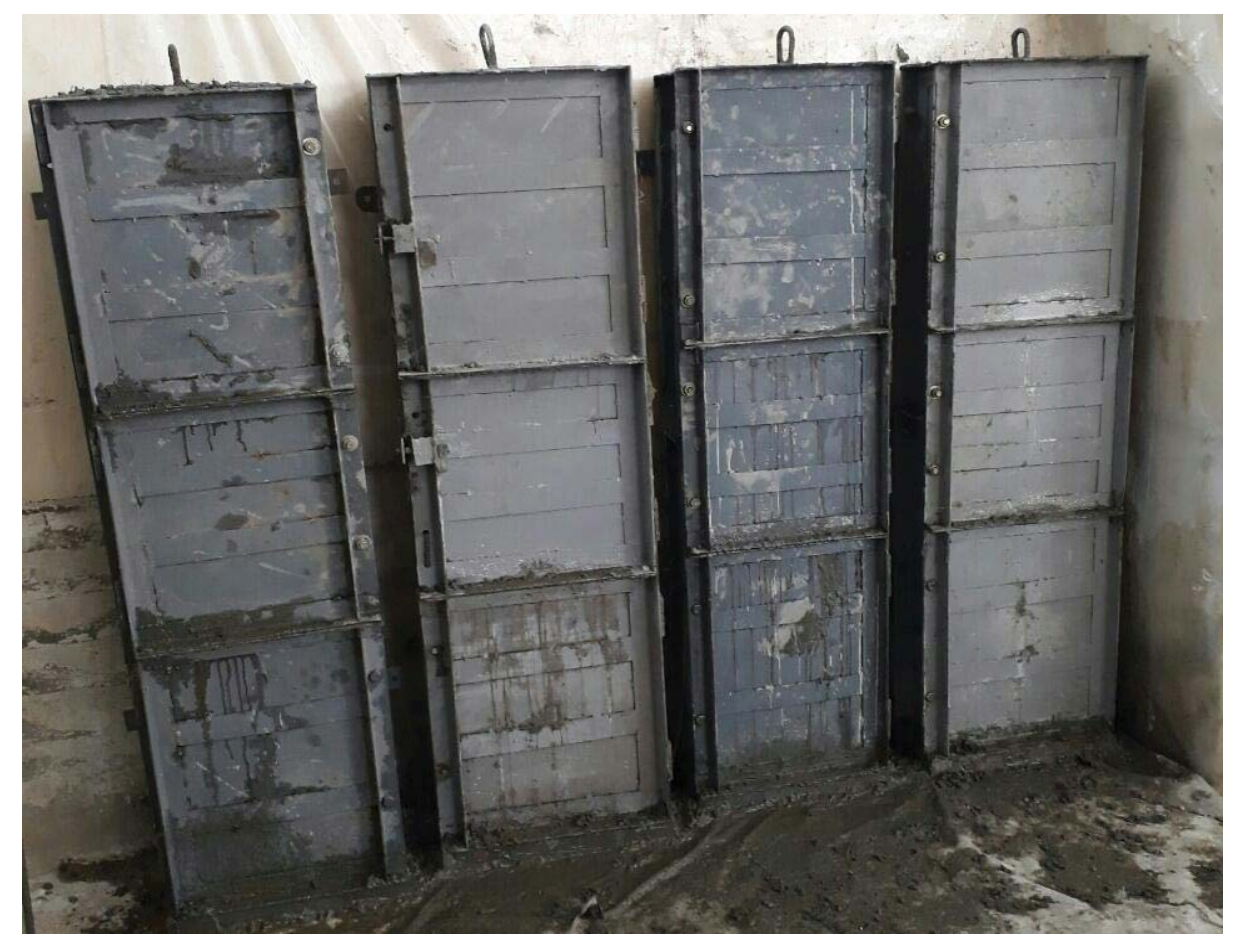

Fig. (2). Steel Molds Used for Casting Hybrid Deep Beams.

\subsection{Test Procedure}

In order to test the beam, the faces of the samples were coated in white color for observing cracks easily. The support and load point locations were positioned and thereafter, the points were mounted on the beams. Too the beams were categorized and the site of support point, loading point, and the digital gage places were noticeable on the beams to ease the accurate setup of testing machine. Thereafter, the beam was elevated by electrical crane and depressed on to supports. Beam specimens were located at the testing machine and checked so that the centerline supports, load arms 
and dial gages were fixed at their right and suitable positions. Loading process commences by application of two point load from the testing machine to the higher face of beam.

All beam specimens have been loaded until failure for monotonic test and five cycles in repeated loading test. The beam samples have been loaded in increases of $10 \mathrm{kN}$, the rate of load increase was around $1.5 \mathrm{kN} / \mathrm{sec}$. The locations and expansion of cracks for each cycle were noticeable on the surface of the beam. Failure happened, while the beam failed abruptly at simultaneity with the load index stopped in record or reoccurrence back and the deflection increased very quick. The ultimate load has been noted, and the load has been removed to permit taking some photographs of the crack pattern and the mode of failure

\section{EXPERIMENTAL RESULTS}

In monotonic loading, At low load levels, the faults in this structure and the cracks did not appear at any spot and the deflections at mid span are slight proportionate to the applied load, because the beams tested behaved in an elastic manner. After the initial flexural cracks was detected and many other flexural cracks, the first diagonal cracks (web shear crack) appears at the diagonal region bounded by load and support positions. Because of the large depth of the beams, observation of the two types of cracking are plainly concurrent, where the flexural crack foregoes the shear crack in most beams while it was delayed in other beams. Since the crack propagates in a manner perpendicular to direction of tension stress, then spread of the flexural cracks through a vertical direction though spread of the shear cracks through a diagonal direction. As the load is otherwise increased, the inclined cracks develop and spread toward the support and load locations. Also, new cracks form similar to the initial shear crack and new cracks form nearer support were appeared. In repeated loading, at the first cycle, the behavior of deep beam specimens were like to the behavior of beams under monotonic loading until the load reached the required load level. Failure occurs by splitting the beam into two parts approximately along the line connecting the brink of steel blocks at the support and load locations expect B-HS-M-Hy2- $\rho_{w} 0$ failed in flexural(crushing compression chord). Details of the tested beams and results obtained are shown in Table 4. Fig. (3a-f) shows mode of failure and the crack pattern of the tested deep beams.

Table 4. Summary of Test Results for Tested Deep Beams.

\begin{tabular}{|c|c|c|c|c|c|c|c|c|}
\hline Beam Designation & Type of Beam & $\mathbf{f}^{\prime} \mathbf{c}$ & $\mathrm{w}$ & SF (\%) & Type of Loading & $\begin{array}{l}\text { No. of } \\
\text { Cycles }\end{array}$ & Pu (kN) & $\begin{array}{l}\text { Mode of } \\
\text { Failure }\end{array}$ \\
\hline$* \mathrm{~B}$-HS-M-Hy1- $\rho_{w} 0$ & Hybrid & 60 & 0.0 & 1 & Monotonic & - & 570 & Diagonal Shear Failure \\
\hline B -HS-R-Hy1- $\rho_{w} 0$ & Hybrid & 60 & 0.0 & 1 & Repeated $(75 \%$ of $*$ B Ultimate Load) & 5 & 440 & Diagonal Shear Failure \\
\hline$* * \mathrm{~B}-\mathrm{HS}-\mathrm{M}-\mathrm{Hy} 2-\rho_{w} 0$ & Hybrid & 60 & 0.0 & 2 & Monotonic & - & 670 & Shear-Flexural Failure \\
\hline B -HS-R-Hy2- $\rho_{w} 0$ & Hybrid & 60 & 0.0 & 2 & Repeated $(75 \%$ of $* *$ B Ultimate Load $)$ & 5 & 530 & Diagonal Shear Failure \\
\hline$* * * \mathrm{~B}-\mathrm{HS}-\mathrm{M}-\mathrm{HSC} 0-\rho_{w}$ & $\begin{array}{l}\text { Non-Hybrid } \\
\text { (HSC) }\end{array}$ & 60 & 0.0 & 0 & Monotonic & - & 520 & Diagonal Shear Failure \\
\hline B -HS-R-HSC $0-\rho_{w} 0$ & $\begin{array}{l}\text { Non-Hybrid } \\
\text { (HSC) }\end{array}$ & 60 & 0.0 & 0 & $\begin{array}{c}\text { Repeated(75\% of } * * * \text { B Ultimate } \\
\text { Load })\end{array}$ & 5 & 420 & Diagonal Shear Failure \\
\hline
\end{tabular}

\subsection{Effect of SF Ratio}

Three volumetric ratios of SF $(0 \%, 1 \%$ and $2 \%)$ were used in this experimental work to investigate the behavior of shear strength for hybrid deep beams under monotonic and repeated loading. These amounts of SF were added to shear span regions of hybrid deep beams. The effect of this variable is studied for beams without web reinforcement and for constant a/h ratio. 


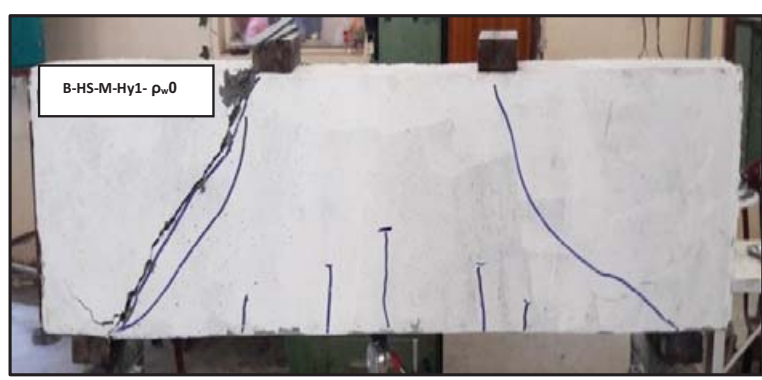

a. Crack Pattern for Beam B-HS-M-Hy1- $\rho_{\mathrm{w}} 0$ after Testing.

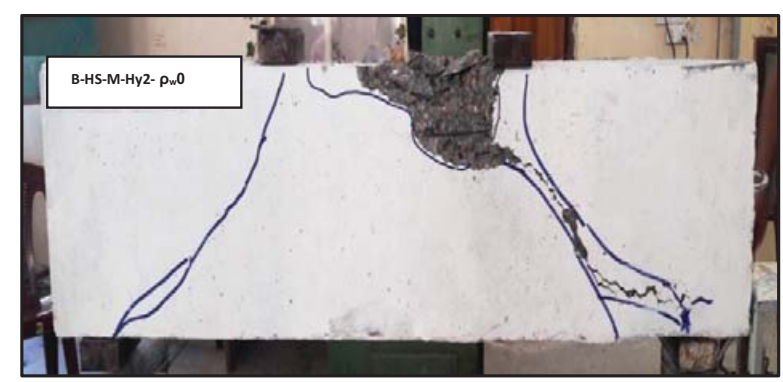

c. Crack Pattern for Beam B-HS-M-Hy2- $\rho_{\mathrm{w}} 0$ after Testing.

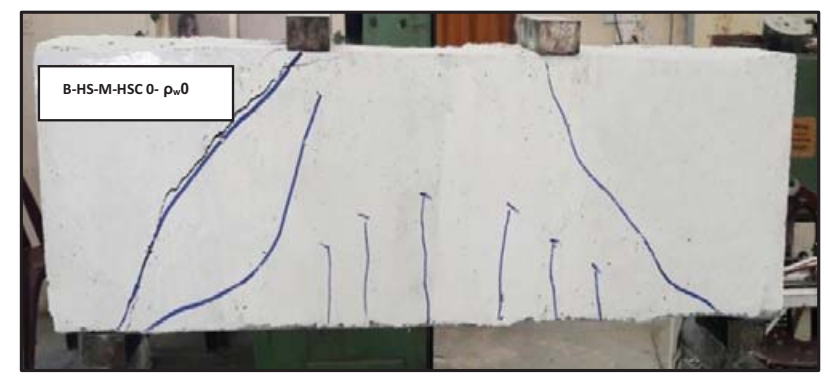

e. Crack Pattern for Beam B-HS-M-HSC $0-\rho_{\mathrm{w}} 0$ after Testing.

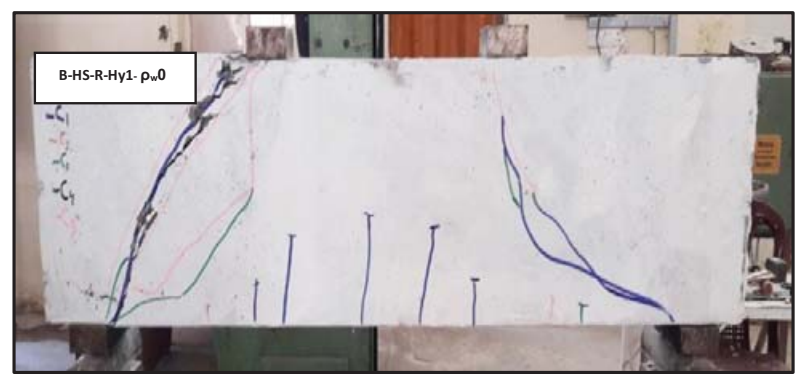

b. Crack Pattern for Beam B-HS-R-Hy1- $\rho_{\mathrm{w}} 0$ after Testing.

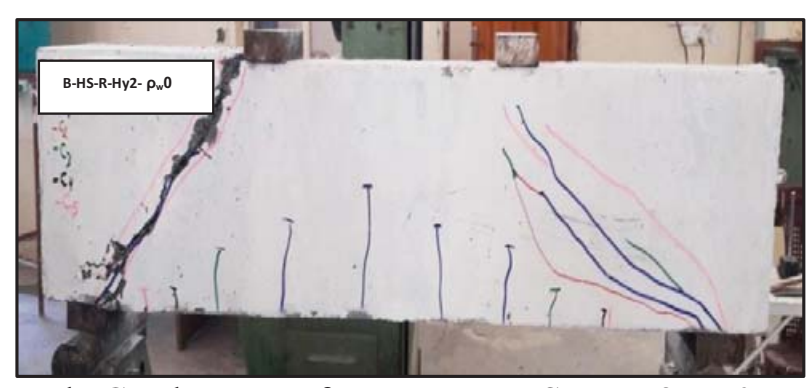

d. Crack Pattern for Beam B-HS-R-Hy2- $\rho_{\mathrm{w}} 0$ after Testing.

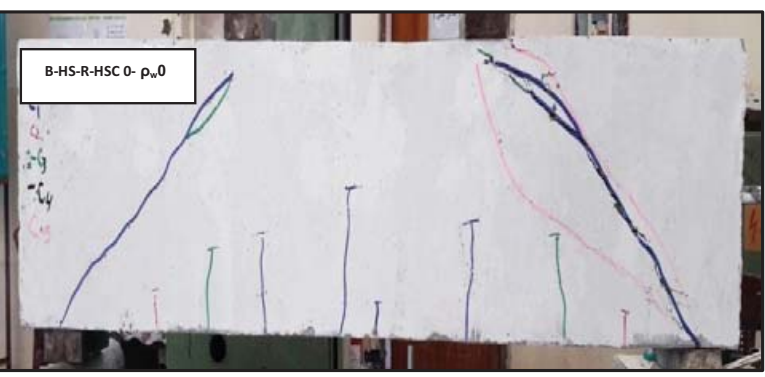

f. Crack Pattern for Beam B-HS-R-HSC 0- $\rho_{\mathrm{w}} 0$ after Testing.

Fig. (3). Mode of failure and the crack pattern of the tested deep beams.

\subsubsection{Under Monotonic Loading}

Results in Table $\mathbf{5}$ show the effect of SF ratio on ultimate loads for deep beams tested under monotonic loading. Table 5. Effect of SF Ratio on Ultimate Load of Beams under Monotonic Loading.

\begin{tabular}{|c|c|c|c|c|c|}
\hline \% Increase Ultimate Load $^{*}$ & $\begin{array}{c}\text { Ultimate Load }(\mathbf{P u}) \\
(\mathbf{k N})\end{array}$ & ${ }_{w} \mathbf{\rho}$ & $\begin{array}{c}\mathbf{S F} \\
(\mathbf{\%})\end{array}$ & $\begin{array}{c}\text { Type of } \\
\text { Beam }\end{array}$ & Beam Designation \\
\hline- & 520 & 0.0 & 0 & $\begin{array}{c}\text { Non }- \text { Hybrid } \\
(\text { HSC })\end{array}$ & B-HS-M-HSC $0-\rho_{w} 0$ \\
\hline 9.62 & 570 & 0.0 & 1 & Hybrid & B-HS-M-Hy1 $-\rho_{w} 0$ \\
\hline$* * 28.85$ & 670 & 0.0 & 2 & Hybrid & B-HS-M-Hy2- $\rho_{w} 0$ \\
\hline
\end{tabular}

"The percentage increase is measured with respect to beam B-HS-M-HSC $0-\rho_{w} 0 .{ }^{* *}$ The percentage increase of load of beam B-HS-M-Hy2- $\rho_{w} 0$ is 17.54 with respect to beam B-HS-M-Hy1- $\rho_{w} 0$. 
The hybrid beam with SF ratio (2\%) failed with crushing compression zone which differs from the other two beams with (B-HS-M-HSC $0-\rho_{w} 0$ and B-HS-M-Hy1- $\left.\rho_{w} 0\right)$ with SF ratio $(0 \%$ and $1 \%)$ that are failed compression strut as shown previously in Fig. (3c) because of the presence of steel fiber in the shear zone with $2 \%$ ratio, which led to the strengthening of the zone and prevent the emergence of cracks and therefore failure occurred in the shear zone, however, in the bending zone steel fiber is not added. This explains the role of steel fiber in increasing tensile strength and prevent or reduce the appearance of cracks.

The ultimate load for hybrid beam with SF ratio of $2 \%$ (B-HS-M-Hy2- $\left.\rho_{w} 0\right)$ and SF ratio of $1 \%$ (B-HS-M-Hy1- $\left.\rho_{w} 0\right)$ increased by $28.85 \%$ and $9.62 \%$, respectively with respect to which beam B-HS-M-HSC $0-\rho_{w} 0$ is cast without SF. The presence of SF in shear span regions for hybrid deep beams contributes in fostering resistance of hybrid deep beams in the absence of web reinforcement. Also, the percentage increase in ultimate load is $17.54 \%$ as the SF ratio increased from $1 \%$ (B-HS-M-Hy1- $\left.\rho_{w} 0\right)$ to $2 \%$ (B-HS-M-Hy2- $\left.\rho_{w} 0\right)$.

\subsubsection{Under Repeated Loading}

Table 6 shows the effect of SF ratio on ultimate load of hybrid deep beams tested under repeated loading level of $75 \%$ of their corresponding control monotonic loading.

From the observation of results in Table 6 it was found that the extension of SF in hybrid beams under repeated loading is significant. The capacity of hybrid deep beams with SF ratio of $2 \%$ and $1 \%$ are increased by $26.19 \%$ and $4.76 \%$, respectively with respect to beam B-HS-R-Hy $1-\rho_{w} 0$. Also, the percentage increase in ultimate load is $20.45 \%$ as the SF ratio increases from $1 \%$ ( B-HS-R-Hy1- $\rho_{w} 0$ ) to $2 \%$ (B-HS-R-Hy2- $\rho_{w} 0$ ). From Tables 5 and 6 it can be concluded that addition of SF with a ratio of $2 \%$ is significant as compared to $1 \%$ for both types of loading (monotonic and repeated) in the absence of web reinforcement.

Table 6. Effect of SF Ratio on Ultimate Load of Beams under Repeated Loading.

\begin{tabular}{|c|c|c|c|c|c|}
\hline \% Increase Ultimate Load $^{*}$ & $\begin{array}{c}\text { Ultimate Load (Pu) } \\
(\mathbf{k N})\end{array}$ & $\begin{array}{c}\text { w } \\
\mathbf{\rho}\end{array}$ & $\begin{array}{c}\mathbf{S F} \\
\mathbf{( \% )}\end{array}$ & $\begin{array}{c}\text { Type of } \\
\text { Beam }\end{array}$ & Beam Designation \\
\hline- & 420 & 0.0 & 0 & Non -Hybrid (HSC) & B-HS-R-HSC 0- $\rho_{w} 0$ \\
\hline 4.76 & 440 & 0.0 & 1 & Hybrid & B-HS-R-Hy1- $\rho_{w} 0$ \\
\hline${ }^{* *} 26.19$ & 530 & 0.0 & 2 & Hybrid & B-HS-R-Hy2- $\rho_{w} 0$ \\
\hline
\end{tabular}

"The percentage of increase is measured with respect to beam B-HS-R-HSC $0-\rho_{w} 0 .{ }^{* *}$ The percentage increase of load of beam B-HS-R-Hy2- $\rho_{w} 0$ is 20.45 with respect to beam B-HS-R-Hy1- $\rho_{w} 0$.

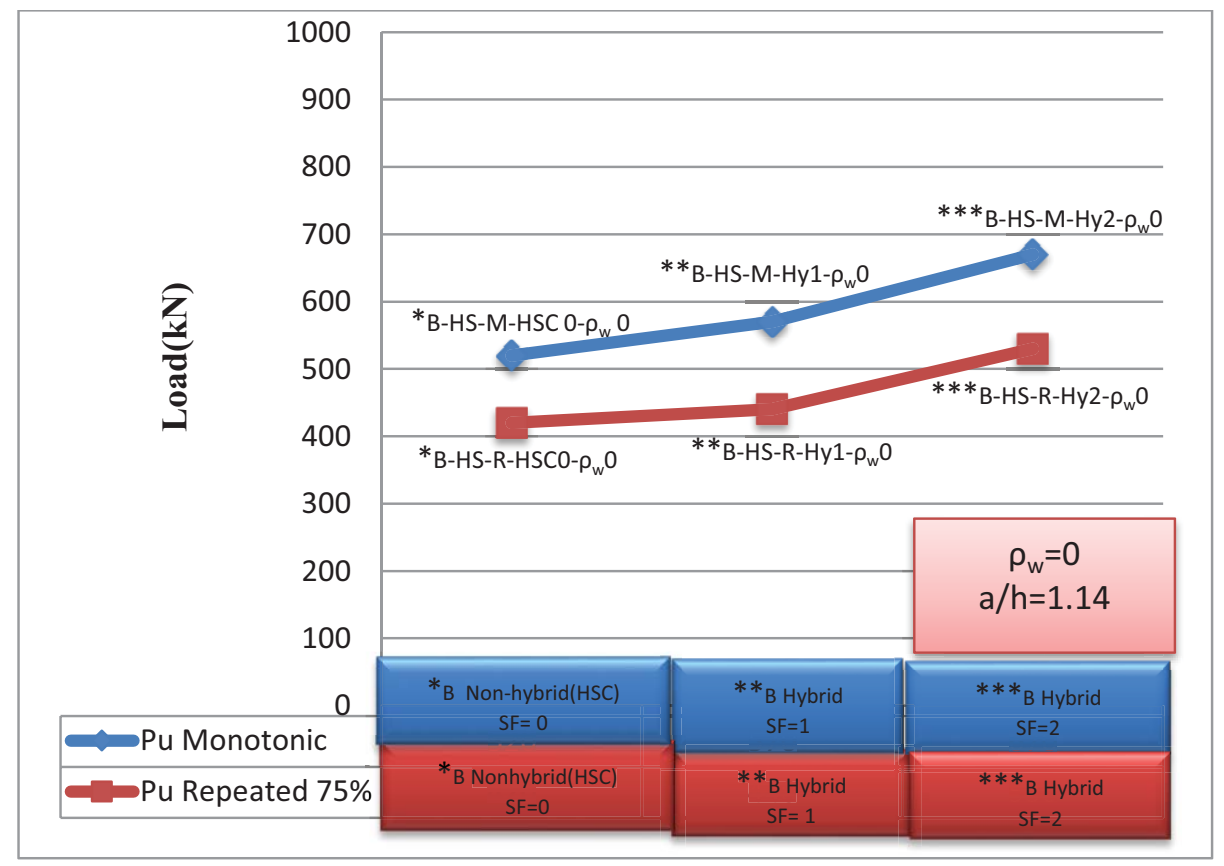

Fig. (4). Effect of SF ratio on ultimate load of beams under monotonic and repeated loading. 
Fig. (4) shows the effect of SF ratio on ultimate load of hybrid deep beams under monotonic and repeated loading of $75 \%$ of control beam failure monotonic loadings.

\subsection{Load-Deflection Response}

Figs. (5a-f) shows the load-deflection response curves obtained for the all tested deep beam specimens which were tested under monotonic and repeated loading.

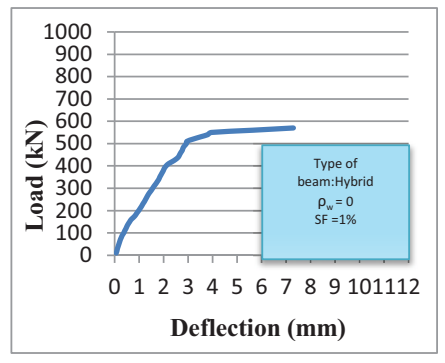

Figure a. Load versus mid span- Deflection

Response for Beam B-HS-M-Hyl- $\rho_{w} 0$

under Monotonic Loading.

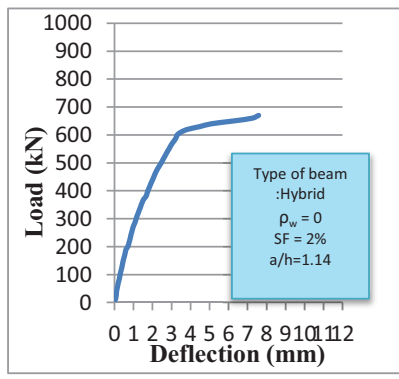

Figure c. Load versus mid span-Deflection

Response for Beam

B -HS-M-Hy2- $\rho_{w} 0$ under Monotonic

$$
\text { Loading. }
$$

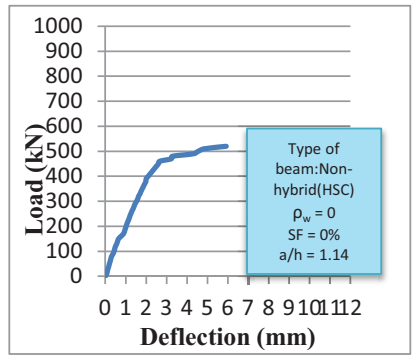

Figure e. Load versus mid span-Deflection Response for Beam

B -HS-M-HSC $0-\rho_{w} 0$ under Monotonic Loading.

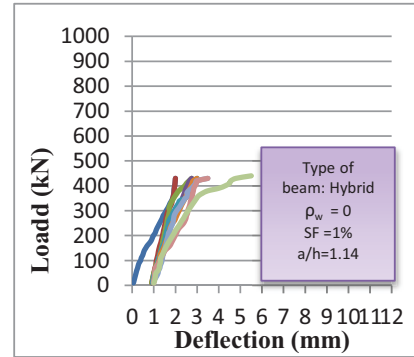

Figure b. Load versus mid span-Deflection

Response for Beam B-HS-R-Hy1- $\rho$ w 0 under Repeated Loading (75\%).

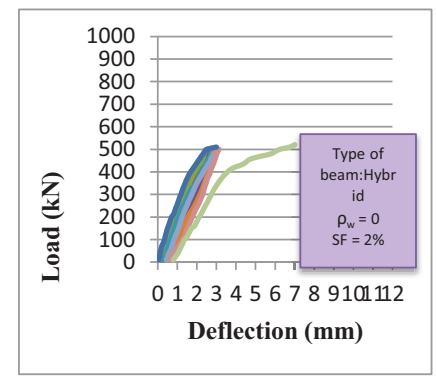

Figure d. Load versus mid span-Deflection Response for Beam

B-HS-R-Hy2- $\rho_{w} 0$ under Repeated Loading

$(75 \%)$.

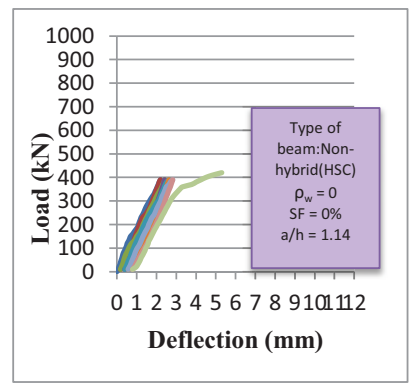

Figure f. Load versus mid span-Deflection Response for Beam

B -HS-R-HSC $0-\rho_{w} 0$ under Repeated Loading

$(75 \%)$.

Fig. (5). The load-deflection response curves obtained for the all tested deep beam specimens. 


\subsubsection{Effect of SF Ratios}

Fig. (6) shows the effect of the extension of SF for hybrid deep beams on load-deflection response under monotonic loading. Three volumetric ratios of SF were used. Hybrid beam with SF ratio of $2 \%$ have the smaller deflection values at each stage of loading as compared to other beams that have SF ratios of $1 \%$ and $0 \%$.

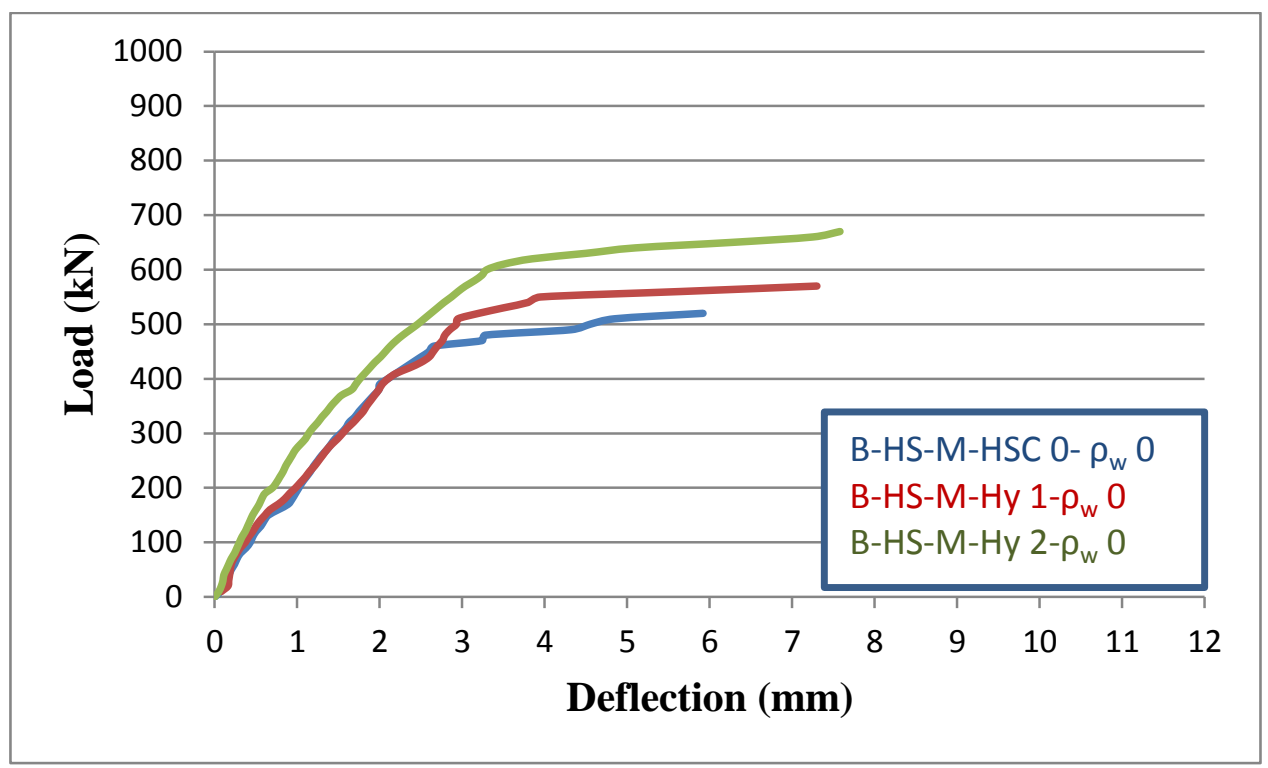

Fig. (6). Load-deflection relationship for hybrid beams with different SF ratios under monotonic loading.

\section{Analytical Work}

Based on the lower-bound theorem, the STM is applied, in which the stress applied on the elements of the STM should not exceed their maximum capacities, and the truss model shall be in equilibrium. When these conditions are met, the truss will exhibit the deformation capacity required by the lower-bound theorem to redistribute the internal stresses and form the arch action [3].

Also, this chapter involves the establishment of the analytical methods that depend on STM techniques for predicting ultimate load of hybrid HSC deep beams to obtain reasonable and accurate methods of analysis of this type of beams in comparison with available experimental data were analyzed using the following analytical methods:

1. STM according to ACI 318R-14Code.

2. Modified STM proposed by Zhang and Tan in March 2007.

3. Modified STM proposed by Zhang and Tan in November 2007, which takes into account size effect of reinforced concrete deep beams.

\subsection{Theory of STM}

STM is a method of designed for reinforced concrete that reduces complex of stress within a structure. STM consists of strut and tie connected at node to form an idealized truss. For idealized truss, the compression members express them struts that symbolize concrete, the tension members express the ties that symbolize by steel reinforcement and nodes are the joints. Fig. (7) shows three elements that the STM consists of. The capacity of a STM according to the lower-bound theory of plasticity will be lower than or at mostly equal to the actual load of structure. Failure of STM can occur happen due to a diagonal splitting in strut, crushing of nodal zone, the ties yielding, or the ties anchorage is a failure [4]. 


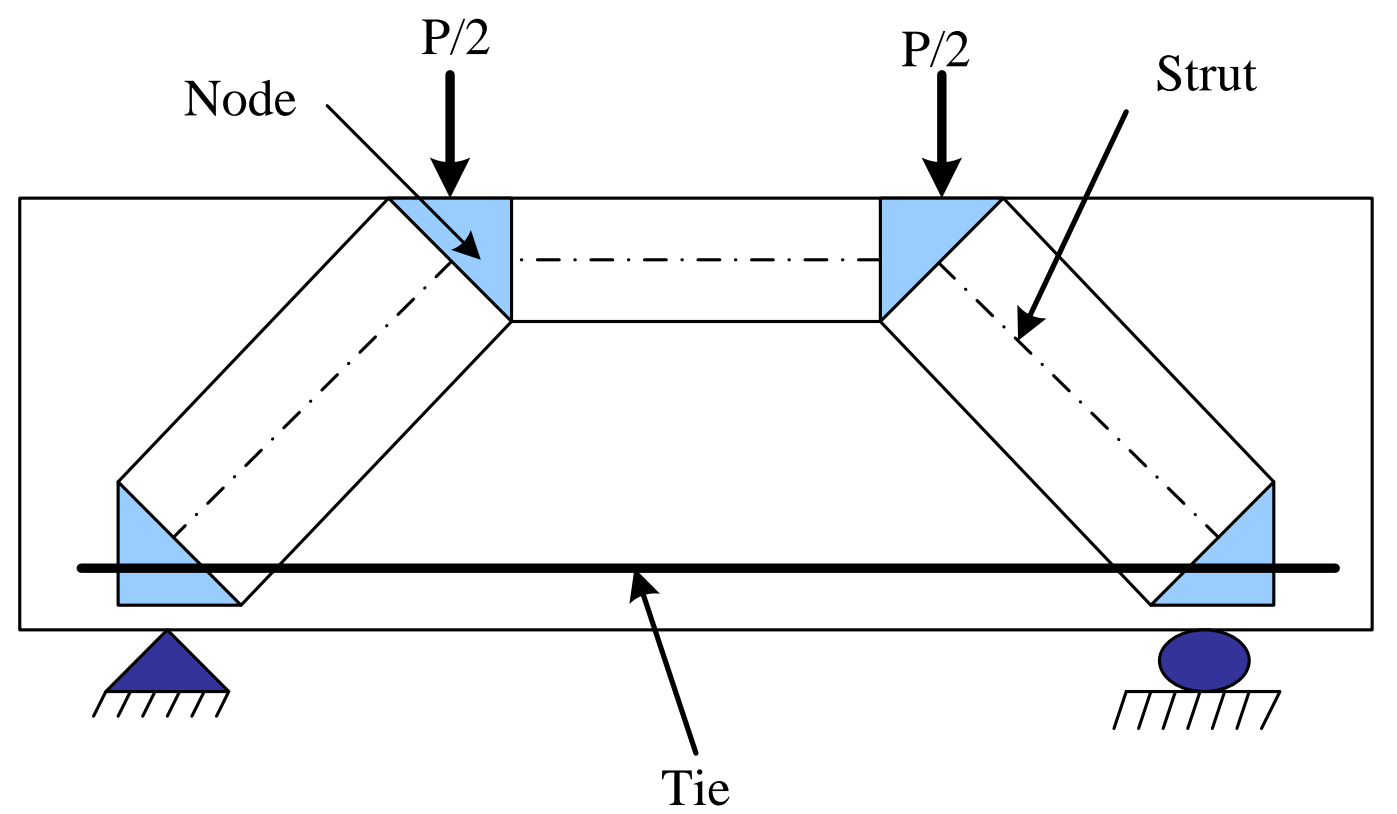

Fig. (7). Strut and Tie Model of deep beam.

\section{ANALYTICAL RESULTS}

\subsection{Comparison of Ultimate Loads Obtained Experimentally and Those Obtained Using Different Analytical Methods}

Analytical methods presented in previous articles are used to obtain the ultimate loads of experimentally tested deep beams which were tested under monotonic loading.

\subsubsection{Capacity of the Tested Deep Beams Utilizing the STM}

In the present work, ultimate load for three simply supported deep beams which were tested under monotonic loading are calculated according to ACI 318 R-14 Code [1]. From the results it can be noticed that the STM mentioned in ACI 318R-14 Code underestimates the load capacity of deep beams for some beams and overestimates capacities for the other beams. The mean value $\left(\mathrm{X}^{\prime}\right)$ of the analytical/test ratio results of ultimate loads $\left(\mathrm{P}_{\mathbf{A n}} / \mathrm{P}_{\text {Exp }}\right)$ is 1.25 where $\mathrm{P}_{\text {An }}$ refers to ultimate loads obtained using analytical methods and $\mathrm{P}_{\mathrm{Exp}}$ refers to ultimate loads obtained from experimental test, the Standard Deviation (SD) is 0.07 and the Coefficient of Variation (CV) is 0.073 .

\subsubsection{Modified STM Theory}

Zhang and Tan in March (2007) [5], submitted a modified STM. Based on a preceding investigation reported by Tan and Cheng [6] can be calculated as shear strength of reinforced concrete deep beams. In this investigation, the shear capacity of 233 simply supported deep beams has been estimated using the modified STM in order to test its adequacy. For these deep beams, concrete strength varied between 16 to $120 \mathrm{MPa}$, which involved high and normal strength concrete. The deep beams had a total depth $\mathrm{h}$ reaching from $200 \mathrm{~mm}$ to $1750 \mathrm{~mm}$ and the a/d ratio reaching from 0.28 to 2.0. The ratio of longitudinal reinforcement reached from $0.90 \%$ to $4.07 \%$, and web reinforcement ratios (vertical and horizontal) reached from $0.0 \%$ to $2.86 \%$ and from $0.0 \%$ to $3.17 \%$, respectively.

For simply supported reinforced concrete beams which were analyzed constructively dependent on symmetric two point loads, it is well known that the ultimate load $(\mathrm{P})$ is equal to twice the shear force at the support (Eqs. 1 and 2 ).

$$
\mathrm{P}=2 V_{n}
$$

The expression for calculation shear strength $\mathrm{V}_{\mathrm{n}}$ according to Zhang and Tan [5], is as follows: 


$$
V_{n}=\frac{1}{\frac{4 \sin \theta_{S} \cos \theta_{S}}{A_{c} f_{t}}+\frac{\sin \theta_{S}}{A_{s t r} f_{C}^{\prime}}}
$$

where;

$V_{n}$ : deep beams shear strength $(\mathrm{N})$.

$A_{c}$ : is the beam active cross sectional area $\left(\mathrm{mm}^{2}\right)$, equals to $\mathrm{b}_{\mathrm{w}} \mathrm{d}_{\mathrm{c}}$.

$\mathrm{d}_{\mathrm{c}}$ : effective beam depth ( $\left.\mathrm{mm}\right)$.

$A_{s t r}:$ the concrete diagonal strut cross sectional area $\left(\mathrm{mm}^{2}\right)$, equal to $\mathrm{w}_{\mathrm{s}} \mathrm{b}_{\mathrm{w}}$

$\mathrm{w}_{\mathrm{s}}$ : active width of the inclined strut $(\mathrm{mm})$.

$\mathrm{b}_{\mathrm{w}}$ : width of deep beam ( $\left.\mathrm{mm}\right)$.

$f_{e}$ : collective tensile strength of concrete and reinforcement ( $\left.\mathrm{MPa}\right)$.

$\theta_{s}$ : angle amid the axis of the strut and the straight axis of the member.

It can be noted that the expression is the composite resistance of tension and included assistances from concrete and reinforcement (main with the web bars), where;

$$
f_{t}=f_{c t}+f_{s t}
$$

$f_{c t}$ : symbolizes the contribution of concrete tensile strength. (Eq. 3)

$f_{s t}$ : symbolizes the contribution of steel reinforcement which contains of 2 parts, fsw from the web reinforcement and fss from the longitudinal reinforcement as explain in equation Eq. 4.

$$
f_{s t}=f_{s w}+f_{s s}
$$

Zhang and Tan submitted that the existence of web reinforcement in the strut restricts the inclined cracks of readily increase into every the strut end. Eq. 5 shows the tensile contribution of web reinforcement at the boundary of the nodal zone.

$$
f_{s w}=\frac{A_{s w} f_{y w} \sin \left(\theta_{s}+\theta_{w}\right)}{A_{c} / \sin \theta_{s}}
$$

For conformity horizontal web reinforcement and cases of vertical, Eq. 6 is reduced to:

$$
f_{S W}=\frac{A_{s v} f_{y v} \sin 2 \theta_{s}}{2 A_{c}}+\frac{A_{s h} f_{y h} \sin ^{2} \theta_{s}}{A_{c}}
$$

Where:

$A_{s v}$ : overall areas of vertical web reinforcement in the shear span $\left(\mathrm{mm}^{2}\right)$.

$A_{s h}$ : overall areas of horizontal web reinforcement in the shear span $\left(\mathrm{mm}^{2}\right)$.

$f_{y v}$ : tensile yield strength of vertical web reinforcement ( $\left.\mathrm{MPa}\right)$.

$f_{y h}$ : tensile yield strength of horizontal web reinforcement (MPa).

$\theta_{s}$ : angle amid the horizontal axis of the member and the axis of the strut.

$\theta_{w}$ : angle amid the horizontal axis of beams and the web reinforcement at the crossing of the reinforcement and the diagonal strut.

The expression $f_{s s}$ refers to the contribution of bottom longitudinal steel, it can be obtained according to the following Eq. 7:

$$
f_{S S}=\frac{4 A_{s} f_{y} \sin \theta_{s}}{A_{c} / \sin \theta_{s}}
$$


Where:

$A_{s}$ total areas of bottom longitudinal main reinforcement $\left(\mathrm{mm}^{2}\right)$.

$f_{y}$ : tensile yield strength of main reinforcement (MPa).

\subsubsection{Size Effect on the Capacity of Deep Beams Using the STM}

According to Zhang and Tan in November 2007 [7] the size influence on shear strength of reinforced concrete deep beams can be investigated, carried out an experimental program containing of 3 collections of 11 samples, they noticed that an increasing of deep beams depth led to decreases in shear strength. The depth effect was not included in their previous expression for calculating shear strength Article (5.1.2). They stated that the causes of size effect in deep beams need then development, so they submitted that the size effect is influenced by strut geometry and boundary conditions.

Zhang and Tan submitted the following modification to Eq. (2) calculate the size effect for ultimate shear strength.

$$
V_{n}=\frac{1}{\frac{4 \sin \theta_{s} \cos \theta_{s}}{A_{c} f_{t}}+\frac{\sin \theta_{s}}{v A_{s t r} f_{c}^{\prime}}}
$$

The term $v$ refers to the efficiency factor calculates for the influence of strut boundary conditions and strut geometry, influence by web reinforcement (Eqs. 8 and 9). The term $v$ is expressed as follows:

$$
v=\xi \times \zeta
$$

where;

$\zeta$ : efficiency factor for the influence of strut geometry.

$\xi$ :efficiency factor for the influence of strut boundary conditions effected by web reinforcement (Eqs $\mathbf{1 0}$ and $\mathbf{1 1}$ ). These variables are expressed as follows:

$$
\begin{aligned}
& \xi=0.8+\frac{0.4}{\sqrt{1+\left(l-w_{s}\right) / 50}} \\
& \zeta=0.5+\sqrt{k d_{s} / l_{s}} \leq 1.2
\end{aligned}
$$

Where,

1: length of strut in mm, as shown in Fig. (8).

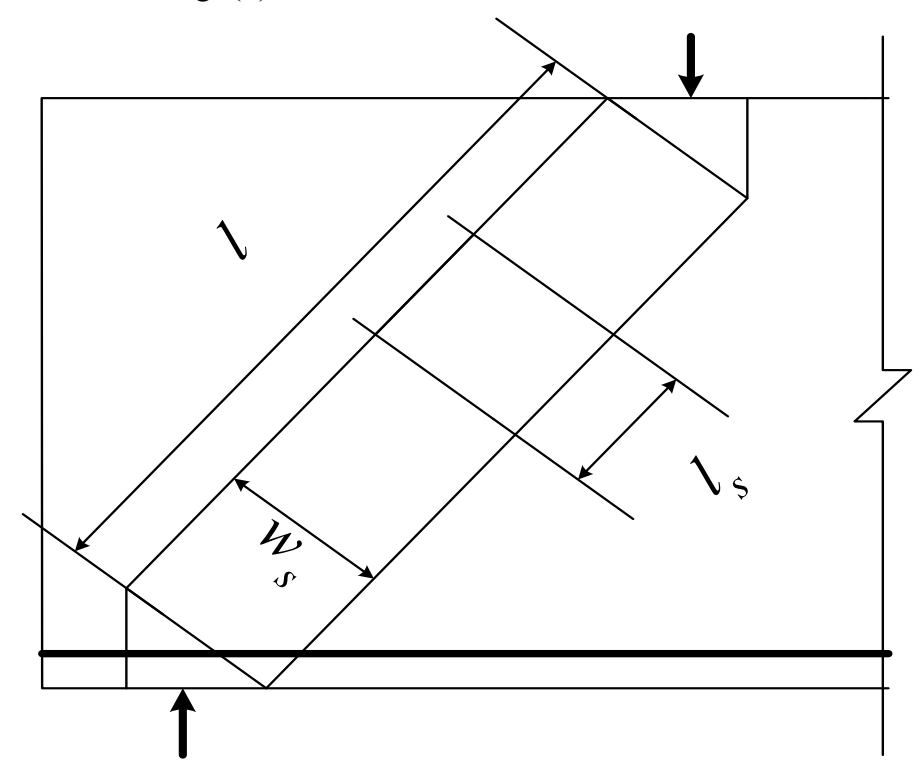

Fig. (8). Strut geometry and strut boundary conditions. 
$d_{s}$ : web steel bar diameter, when web steel is not providing, $d_{s}$ is taken as the smallest diameter of bottom longitudinal steel bars.

$1_{s}$ : maximum spacing of web steel stopped by the inclined strut, when not provided web steel, $1_{s}$ is equal to 1 .

$k=0.5 \times \sqrt{\pi f_{y} / f_{c t}}$ is a material factor, when not providing web steel, it is taken as half of the overhead value.

These results for three methods are shown in Table 7 and Fig. (9).

Table 7. Comparison between Ultimate Loads Obtained Using Experimental Results and Different Analytical Methods.

\begin{tabular}{|c|c|c|c|c|}
\hline \multirow{2}{*}{ Beam Designation } & & \multicolumn{3}{|c|}{$\mathbf{P}_{\text {An. }}$} \\
\cline { 3 - 5 } & $\begin{array}{c}\mathbf{P}_{\text {Exp. }} \\
(\mathbf{k N})\end{array}$ & $\begin{array}{c}\text { STM ACI } \\
\text { 318R-14Code } \\
(\mathbf{k N})\end{array}$ & $\begin{array}{c}\text { Modified STM } \\
\text { by Zhang and } \\
\text { Tan } \\
(\mathbf{k N})\end{array}$ & $\begin{array}{c}\text { *Modified STM } \\
\text { by Zhang and } \\
\text { Tan } \\
(\mathbf{k N})\end{array}$ \\
\hline B-HS-M-Hy 1- $\rho_{w} 0$ & 570 & 567 & 778 & 797 \\
\hline B-HS-M-Hy 2- $\rho_{w} 0$ & 670 & 582 & 877 & 901 \\
\hline B-HS-M-HSC 0- $\rho_{w} 0$ & 520 & 527 & 748 & 763 \\
\hline $\mathrm{X}\left(\mathrm{P}_{\mathrm{An}} / \mathrm{P}_{\mathrm{Exp}}\right)$ & & 1.25 & 1.17 & 1.32 \\
\hline $\mathrm{SD}$ & & 0.07 & 0.26 & 0.27 \\
\hline $\mathrm{CV}$ & 0.073 & 0.22 & 0.2 \\
\hline
\end{tabular}

* Size Effect on the Capacity of Deep Beams Using the STM.

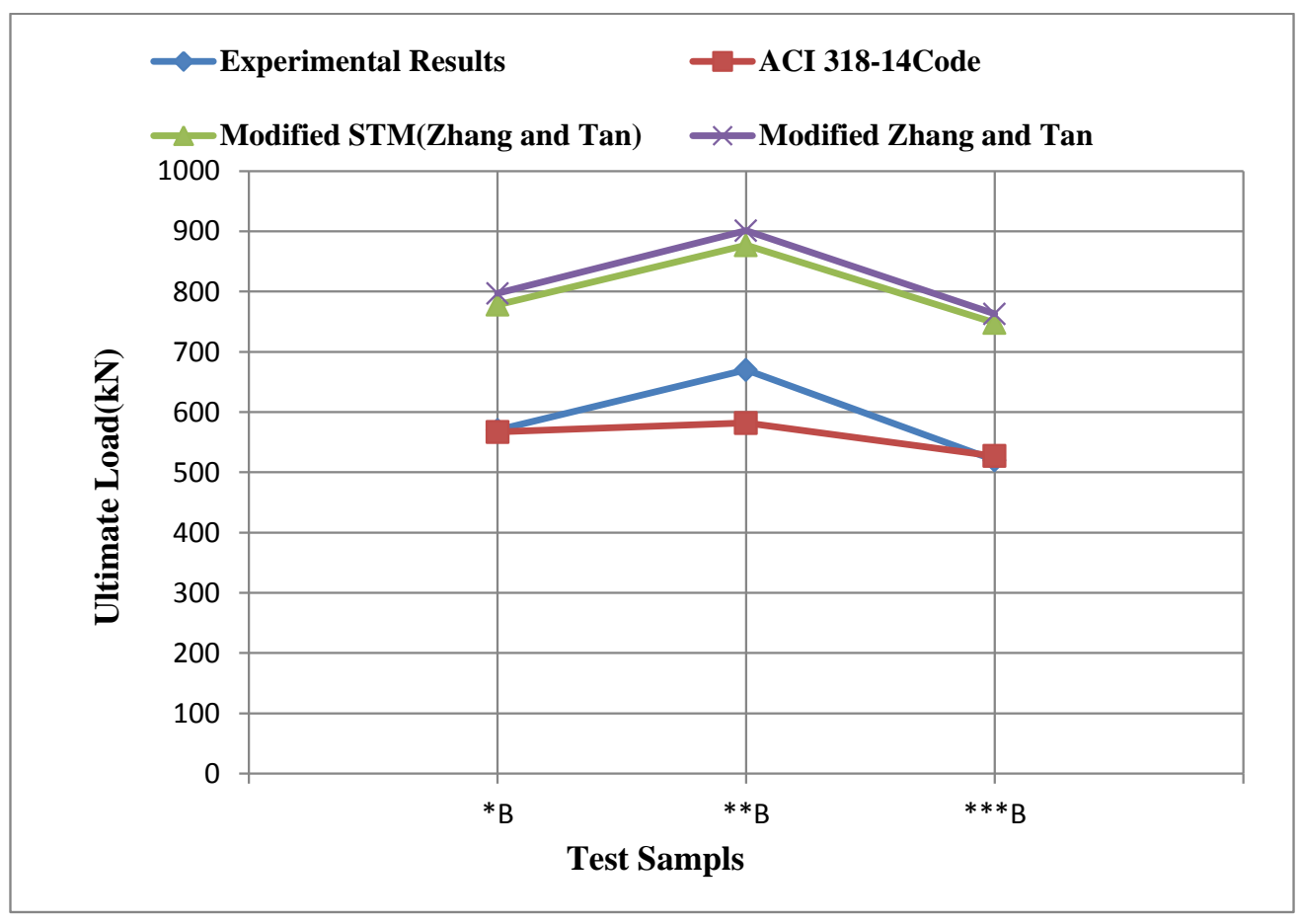

Fig. (9). Ultimate loads obtained using experimental and different analytical methods.

\section{EFFECT OF STEEL-FIBER CONTENT ON STM CALCULATIONS}

We can notice the effect of steel fiber content on STM calculations because in the mentioned method (5.1.1) a compressive strength of concrete $\left(\dot{f}_{c}\right)$ which enhances the presence of steel fiber. Moreover, for other methods (5.1.2) and (5.1.3) effect of steel fiber when use tensile strength concrete $f_{c}$ and compressive strength concrete $\left(f_{c}\right)$ can be seen, that enhances the presence of steel fiber with different ratios. We consider steel fiber improvement tensile strength with particularly. 


\section{CONCLUSION}

\section{Experimental Stage}

The presentage of steel fibers in (HSC) beams increases the ultimate load. It was found that using SF in shear span of the tested deep beams under monotonic loading for hybrid beam with a/h=1.14 for all beams and (SF $1 \%$ ) increased by $9.62 \%$ as compared with non-hybrid beam (SF 0\%), Also, increases in ultimate load for hybrid beam ( SF $2 \%$ ) $28.85 \%$ as compared with non-hybrid beam were found (SF $0 \%$ ) and the increases in the ultimate for hybrid beam (SF 2\%) $17.54 \%$ as compared with hybrid beam (SF 1\%) were found. In repeated loading for hybrid beam (SF $1 \%$ ) increased by $4.76 \%$ as compared with non-hybrid beam (SF 0\%). Furthermore, it was found that increases in ultimate load for hybrid beam (SF 2\%) 26.19\% as compared with non-hybrid beam (SF 0\%) and the increases in the ultimate for hybrid beam (SF 2\%) 20.45\% as compared with hybrid beam (SF 1\%). Therefore, we conclude the presence of steel fiber with ratio $2 \%$ in shear span which led to increase tensile strength, prevent or reduce the appearance of cracks and increase capacity of beam.

\section{Analytical Stage}

1. Results of ultimate loads ACI 318R-14 Code are conservative values compared to the conforming experimental ones but it can be noticed that the STM underestimates the load capacity for some beams and overestimate for other beams. The average amount $\left(\mathrm{X}^{\prime}\right)$ for the analytical/test ratio ultimate loads results $\left(\mathrm{P}_{\mathrm{An}} / \mathrm{P}_{\text {Exp }}\right)$ is 1.25 , the Standard Deviation (SD) is 0.07 and the Coefficient of Variation (CV) is 0.073 .

2. The modified STM developed by Zhang and Tan in March 2007 overrate ultimate loads as compared to test results expect B-HS-M-Hy $1-\rho_{\mathrm{w}} 6$ gives in test result higher than modified STM. The $\mathrm{X}^{\prime}$ is 1.17 , the SD is 0.26 and the $\mathrm{CV}$ is 0.22 .

3. The modified STM developed by Zhang and Tan in November 2007, that includes the effect of size factor, overrate ultimate loads as compared to test results except B-HS-M-Hy1- $\rho_{w} 6$ gives in test result higher than modified STM. The $\mathrm{X}^{\prime}$ is 1.32 , the $\mathrm{SD}$ is 0.27 and the $\mathrm{CV}$ is 0.2 .

\section{LIST OF ABBREVIATIONS}

$\begin{array}{lll}\text { ACI } & = & \text { American Concrete Institutes } \\ \text { CHSC } & = & \text { Conventional High Strength Concrete } \\ \text { M } & = & \text { Monotonic } \\ \text { R } & = & \text { Repeated } \\ \text { FHSC } & = & \text { Fibrous High Strength Concrete } \\ \text { SD } & = & \text { Standard Deviation } \\ \text { SF } & = & \text { Steel Fibers } \\ \text { STM } & = & \text { Strut and Tie Models } \\ \text { CV } & = & \text { Coefficient of Variation }\end{array}$

\section{CONSENT FOR PUBLICATION}

Not applicable.

\section{CONFLICT OF INTEREST}

The authors declare no conflict of interest, financial or otherwise.

\section{ACKNOWLEDGEMENTS}

Declared None.

\section{REFERENCES}

[1] ACI Committee, 318R, "Building Code Requirement for Structural Concrete and Commentary, American Concrete Institute: Farmington Hills, Michigan, 2014.

[2] M. Shahnewaz, "Shear Behavior of Reinforced Concrete Deep Beam under Static and Dynamic Load", M.SC. Thesis, University of British, Columbia, Vancouver, Canada, 2013. 
[3] K. Mohamaed, A. S. Farghaly, and B. Benmokran, "Proposed Strut and Tie Model for Concrete Deep Beams Reinforced with FRP Bars", PhD Thesis, University de Sherbrooke, London, Canada, pp. 1-4 2006.

[4] D. Birrcher, R. Tuchscherer, M. Huizinga, O. Bayrak, S. Wood, and J. Jirsa, "Strength and Serviceability Design of Reinforced Concrete Deep Beams", CTR Technical Report, December, 2008.

[5] N. Zhang, and K.H. Tan, "Direct Strut-and-Tie model for single span and continuous deep beams", Sci. Direct, Eng. Struct. J., vol. 29, no. March, pp. 2987-3001, 2007.

[http://dx.doi.org/10.1016/j.engstruct.2007.02.004]

[6] K.H. Tan, and H.K. Lu, "Shear behavior of large reinforced concrete deep beams and code comparisons", ACI Journal, vol. 96, no. 5, pp. 836-845, 1999.

[7] N. Zhang, and K.H. Tan, "Size effect in RC deep beams: Experimental investigation and STM verification", Sci. Direct, Eng, Struct. J., vol. 29, no. November, pp. 3241-3254, 2007.

[http://dx.doi.org/10.1016/j.engstruct.2007.10.005]

(C) 2018 Hassan and Mhebs.

This is an open access article distributed under the terms of the Creative Commons Attribution 4.0 International Public License (CC-BY 4.0), a copy of which is available at: (https://creativecommons.org/licenses/by/4.0/legalcode). This license permits unrestricted use, distribution, and reproduction in any medium, provided the original author and source are credited. 